\title{
Influence of various dietary fat sources on freezing capacity of Moghani ram semen
}

\author{
N. Hedayat-Evrigh ${ }^{1 \#}$, F. Moradi $^{1}$, V. Vahedi ${ }^{2}$, B. Navidshad ${ }^{1} \&$ A. Seifi-Jamadi ${ }^{3}$ \\ ${ }^{1}$ Department of Animal Science, Faculty of Agricultural \& Natural Resources, University of Mohaghegh Ardabili, \\ Ardabil, Iran \\ ${ }^{2}$ Department of Animal Science, Moghan College of Agriculture \& Natural Resources, University of Mohaghegh \\ Ardabili, Ardabil, Iran \\ ${ }^{3}$ Department of Animal Science, College of Agriculture \& Natural Resources, University of Tehran, Karaj, Iran
}

(Received 22 May 2018; Accepted 5 May 2019; First published online 8 June 2019)

\author{
Copyright resides with the authors in terms of the Creative Commons Attribution 4.0 South African License. \\ See: http://creativecommons.org/licenses/by/4.0/za \\ Condition of use: The user may copy, distribute, transmit and adapt the work, but must recognize the authors and \\ the South African Journal of Animal Science.
}

\begin{abstract}
The aim of this study was to investigate the effects of dietary supplementation of protected fish oil (FO) and Persia fat ${ }^{\circledR}$ (PF) on the quality of Moghani ram semen. For this purpose, a total of 96 ejaculates were collected from 12 healthy mature Moghani rams, which were divided into three distinct groups $(n=4)$ and were assigned to one of three experimental diets. The first group (control) received a diet supplemented with palm oil (PO), while the second and third groups received encapsulated FO and PF, respectively. After primary evaluation, semen samples of each group were pooled to eliminate individual differences, and then evaluated for semen concentration and volume. Afterwards, the samples were diluted with a Tris-based extender and frozen with a standard protocol. After thawing, motion kinetics, viability, membrane functionality and abnormality were assessed. The results showed that the group that received FO had significanty higher viability (quadratic), progressive motility (PM) (\%), average path velocity (VAP) ( $\mu \mathrm{m} / \mathrm{s})$, curvilinear velocity $(\mathrm{VCL})(\mu \mathrm{m} / \mathrm{s})$ (linear), amplitude of lateral head displacement (ALH) $(\mu \mathrm{m})$ (quadratic) and sperm concentration (linear) than the others. Additionally, total motility (TM) (\%) and straight-line velocity (VSL) $(\mu \mathrm{m} / \mathrm{s})$ were significantly higher in the groups that received FO and PF compared with the control (quadratic) The results indicated that sperm abnormalities in the control group were significantly higher than the other groups. In conclusion, enrichment of the diet with FO or Persia fat could enhance ram sperm quality after freeze-thawing process.
\end{abstract}

Keywords: fish oil, frozen spermatozoa, ram, motion parameters

\# Corresponding author: nhedayat@uma.ac.ir

\section{Introduction}

Lipids are an integral part of cell membrane bilayers, which play a pivotal role in cell functions. Phospholipids, sterols and triglycerides are the best-known lipids in animal cell walls. Also, cell wall fatty acids (FA) and unsaturated/saturated fatty acid ratio are more effective. Animals cannot synthesize n- 6 and n-3 fatty acids de novo owing to a lack of appropriate fatty acid desaturase enzymes and the need to obtain these fatty acids from their diet (Wathes et al., 2007). In addition, dietary FA are known to affect the FA composition of sperm membranes in humans (Conquer et al., 2000), bulls (Moallem et al., 2015), stallions (Brinsko et al., 2005; Rodrigues et al., 2017), pigs (Cook \& McMaster, 2002) and roosters (Cerolini et al., 2006). In many mammalian species, the plasma membrane has more than $60 \%$ polyunsaturated fatty acids (PUFAs), although sperm membrane lipids vary between species (Saether et al., 2007).

Mammalian sperm plasma is characterized by a high proportion of PUFAs, which play an important role in the fluidity and flexibility of the plasma membrane. On the other hand, plasma membrane functionality is a crucial factor in preserving sperm viability and fertilizing capacity. This physiological exclusivity may improve sperm resistance against stresses such as cold shock. A high concentration of docosahexaenoic acid (DHA) has been positively associated with sperm motility in human semen and sperm (Ollero et al., 2001). 
Lipids are used as fuel for Sertoli cells, and in membrane remodelling of developing germ cells (Rato et al., 2014). For this purpose, fatty acids should accumulate in testicular cells through two processes: i) passive diffusion through the lipid bilayer and ii) protein-facilitated transport that is mediated by CD36 glycoprotein, which is widely expressed in Sertoli cells.

Mammalian testicular cells and spermatozoa contain high amounts of C20:4, C20:5, C22:5 and C22:6 FA (n-3 and n-6 PUFAs), derived from dietary linoleic (C18:2) and linolenic acids (C18:3), elongation and desaturation process (Rato et al., 2014). Thus, decreasing PUFAs in sperm plasma membranes leads to decreases in motility and viability owing to cryoinjury in the freeze-thawing process (Tran et al., 2016). Persia fat $^{\circledR}$ (PF) is an Iranian product with the same concentration of $n-3$ and n-6 FA as supplementary fat. Many studies have demonstrated that dietary n-3 and n-6 fatty acids enhance the preservation of spermatozoa after cold shock and ice crystal formation in humans (Vireque et al., 2016), bulls (Gholami et al., 2010; Khoshvaght et al., 2016), goats (Dolatpanah et al., 2008), stallions (Rodrigues et al., 2017) and roosters (Cerolini et al., 2006). On the other hand, Karimi et al. (2017) demonstrated that supplementation of the diet of bulls with conjugated linoleic acid (CLA) did not affect fresh and frozen semen quality. To the best of the authors' knowledge, there is a dearth of information about the effects of dietary supplementation of n-3 and n-6 fatty acids on sperm motion kinematics in rams. Therefore, this study was conducted to investigate the protective effects of three lipid sources on the semen quality of cold-stressed Moghani rams

\section{Material and Methods}

Eosin Y (CAS no. 15086-94-9), nigrosin (CAS no. 101357-32-8), Tris (CAS no. 77-86-1), citric acid (CAS no. 77-92-9), fructose (CAS no. 57-48-7) and sodium citrate (CAS no. 6132-54-3) were obtained from Sigma \& Merck (St. Louis, MO, USA).

Semen samples were collected from 12 healthy mature Moghani rams (3 - 5 years old, weight 60 - 70 $\mathrm{kg}$ ). Rams were housed at the Moghani Sheep Husbandry and Breeding Centre in Ardabil, Jaafar Abad, Iran (39 38'49"N 48 02'23"E), and were maintained under uniform management conditions. Before the beginning of the experiment, rams were classified according to their subjective sperm motility (good versus moderate to poor quality). Afterwards, they were divided into three equal groups $(n=4)$, which were randomized according to their sperm motility. Each group included one poor semen quality ram $(60 \% \leq \mathrm{TM} \leq 70 \%)$, one moderate $(70 \% \leq \mathrm{TM} \leq 80 \%)$ and two good (TM $\leq 80 \%)$ semen quality rams. They received one of the experimental isoenergetic and isonitrogenic diets, which were enriched with fat sources (3\% dry matter intake) (Table 1). The first group (control) received a diet supplemented with palm oil (PO), while the second and third groups received encapsulated fish oil (FO) ( $\mathrm{n}-3$ source) and PF (Kimia Danesh Alvand Co, Qom, Iran) (Table 2). The rams were feed the experimental diets from two weeks before sample collection until eight weeks throughout it. A total of 96 ejaculates were collected weekly from 12 rams (eight weeks) (each collection time was regarded as an experimental repeat) during the non-breeding season using an artificial vagina (IMV Technologies, L'Aigle, Basse-Normandie, France). Rams were stimulated for ejaculation by a ewe that received a dose of oestradiol $(0.5 \mathrm{~mL})$ one day prior to collection to show oestrus behaviour. Immediately after collection, the ejaculates were immersed in a warm water bath at $37^{\circ} \mathrm{C}$ until assessment in the laboratory (utmost $30 \mathrm{~min}$ ). The ejaculates with a volume $0.75-2 \mathrm{~mL}$, sperm concentration $\geq 2.5 \times 10^{9}$ sperm $/ \mathrm{mL}$, TM $\geq 60 \%$, and sperm abnormalities $<10 \%$ were used for cryopreservation. To eliminate individual differences in each group, semen samples $(n=4)$ were pooled, evaluated for semen concentration and volume, and then processed for freezing process (Seifi-Jamadi et al., 2017).

The Tris-based extender used in this study comprised $253.42 \mathrm{mM}$ Tris, $85.36 \mathrm{mM}$ citric acid, $70 \mathrm{mM}$ fructose, and $500 \mathrm{IU} / \mathrm{mL}$ penicillin (Shafa Farmed Co, Iran) and 20\% (v/v) egg yolk. The osmolarity and pH of this base extender were set at $325-350 \mathrm{mOsm} / \mathrm{Kg}$ and $6.9-7.1$, respectively. For each group, the pooled ejaculates were diluted with the basic extenders. After dilution, the final sperm concentration was $200 \times 10^{6}$ spermatozoa/mL. The diluted semen samples were loaded into $0.25 \mathrm{~mL}$ straws (IMV Technologies, France) sealed with polyvinyl alcohol, and equilibrated at $5{ }^{\circ} \mathrm{C}$ for $150 \mathrm{~min}$. After equilibration, the straws were frozen in liquid nitrogen $\left(\mathrm{LN}_{2}\right)$ vapours resting $4 \mathrm{~cm}$ above the liquid nitrogen for 12 min (Najafi et al., 2013 ). Afterwards, the straws were plunged into liquid nitrogen $\left(\mathrm{LN}_{2}\right)$ for storage. For post-thaw evaluation, the frozen straws were thawed individually at $37^{\circ} \mathrm{C}$ for 30 seconds in a water bath. Sperm evaluation was performed immediately after thawing (Uysal \& Bucak, 2007).

Sperm motility parameters were analysed using a Casa system (VideoTesT ${ }^{\circledR}$, Sperm 3.1, Russia) equipped with a phase contrast microscope (Labomed® Lx400, USA). These variables were recorded for TM (\%), PM) (\%) VSL( $\mu \mathrm{m} / \mathrm{s}), \operatorname{VCL}(\mu \mathrm{m} / \mathrm{s})$, VAP $(\mu \mathrm{m} / \mathrm{s})$, LIN (\%), amplitude of lateral head displacement $(\mathrm{C})(\mu \mathrm{m})$, straightness (STR) (\%), and beat/cross frequency (BCF) $(\mathrm{Hz})$.

Viability was assessed through eosin-nigrosin staining (Björndahl et al., 2003) The sperm suspension smears were prepared by mixing $5 \mu \mathrm{L}$ semen sample with $5 \mu \mathrm{L}$ eosin-nigrosin stain on a warm slide and then smeared. The viability was assessed by counting 200 cells under phase-contrast microscopy at 400x. Sperm 
with white (unstained), light pink heads or a red appearance restricted to the neck region (leaky neck) were considered alive, while those with stained or partial stained heads were regarded as dead (WHO, 2010).

Table 1 Ingredients and composition of the experimental diets that were used as treatments

\begin{tabular}{|c|c|c|c|}
\hline \multirow{2}{*}{ Feed Ingredient } & \multicolumn{3}{|c|}{ Experimental diets (\%) } \\
\hline & Fish oil & Persia fat & Palm oil \\
\hline Alfalfa hay & 27.47 & 27.47 & 27.47 \\
\hline Corn silage & 24.50 & 24.50 & 24.50 \\
\hline Straw & 10.50 & 10.50 & 10.50 \\
\hline Barley & 20.17 & 20.13 & 20.13 \\
\hline Wheat bran & 12.50 & 12.54 & 12.54 \\
\hline $\mathrm{CaCO}_{3}$ & 1.00 & 1.00 & 1.00 \\
\hline Premix (vitamin) $^{a}$ & 0.50 & 0.50 & 0.50 \\
\hline Salt & 0.36 & 0.36 & 0.36 \\
\hline Fish oil & 3.00 & - & - \\
\hline Persia fat & - & 3.00 & - \\
\hline Palm oil & - & - & 3.00 \\
\hline
\end{tabular}

${ }^{a}$ Each $\mathrm{kg}$ of the vitamin-mineral premix contained: vitamin A: $50000 \mathrm{IU}$; vitamin $\mathrm{D}_{3}: 10000 \mathrm{IU}$; vitamin E: $0.1 \mathrm{~g}$; calcium: 196 g; phosphorus: 96 g; sodium: 71 g; magnesium: 19 g; iron 3 g; copper: 0.3 g; manganese: 2 g; zinc: 3 g; cobalt: $0.1 \mathrm{~g}$; iodine: $0.1 \mathrm{~g}$; selenium: $0.001 \mathrm{~g}$

Table 2 Fatty acid composition of the rams experimental diets

\begin{tabular}{lccc}
\hline \multirow{2}{*}{$\begin{array}{l}\text { Fatty acids } \\
\text { (g/100 g FA) }\end{array}$} & Fish oil & Experimental diet \\
\cline { 2 - 4 } & 3.67 & Persia fat & Palm oil \\
\hline $14: 0$ & 26.17 & 2.86 & 2.23 \\
$16: 0$ & 6.74 & 22.23 & 45.04 \\
$16: 1$ & 11.01 & 3.03 & 1.01 \\
$18: 0$ & 18.04 & 10.43 & 12.35 \\
$18: 1$ & 9.34 & 21.12 & 15.06 \\
$18: 2$ (n-6) & 6.87 & 19.03 & 11.67 \\
$18: 3$ (n-3) & 0.51 & 8.52 & 0.81 \\
$20: 0$ & 0.42 & 0.48 & 0.52 \\
$20: 4$ (n-6) & 1.54 & 0.39 & 0.26 \\
$20: 5$ (n-3) & 0.31 & 0.32 & 0.15 \\
$22: 5$ (n-6) & 4.36 & 0.71 & 0.42 \\
$22: 6$ (n-3) & 11.02 & 1.43 & -- \\
Unknown FA & 1.27 & 9.45 & 10.48 \\
n-3/n-6 ratio & & 0.51 & 0.08 \\
\hline
\end{tabular}

The hypo-osmotic swelling test (HOST) was used to assess the functional functionality (MF) of the sperm membrane. The HOST was performed by incubating $30 \mu \mathrm{L}$ semen with $300 \mu \mathrm{L}$ of a 100 mOsm hypoosmotic solution ( $0.9 \mathrm{~g}$ fructose and $0.49 \mathrm{~g}$ sodium citrate dissolved in $100 \mathrm{~mL}$ distilled water) at $37^{\circ} \mathrm{C}$ for 30 min (Rahmatzadeh et al., 2017). After incubation, $10 \mu \mathrm{L}$ of the mixture was placed on a glass slide and covered with a cover slip to evaluate under a phase-contrast microscope $(\times 400)$. A total of 200 spermatozoa 
were counted in at least five microscopic fields. Then the percentage of spermatozoa with swollen and curled tails was recorded. Swelling is characterized by a coiled tail, indicating that the plasma membrane is intact (Seifi-Jamadi et al., 2016a).

The sperm abnormalities were observed by adding three drops of each semen sample to a tube containing $1 \mathrm{~mL}$ Hancock solution $62.5 \mathrm{~mL}$ formalin $37 \%$, $150 \mathrm{~mL}$ sodium saline, $1.8 \mathrm{~g} / 100 \mathrm{~mL}$ double distilled water, $150 \mathrm{~mL}$ buffer solution (including $\mathrm{Na}_{2} \mathrm{HPO}_{4}$ and $\mathrm{K}_{2} \mathrm{HPO}_{4}$ in distilled water) (Schäfer \& Holzmann, 2000). One drop of this mixture was placed on a microscope slide and covered with a cover slip. The percentages of total sperm abnormalities (acrosome and caput abnormalities, detached heads, abnormal mid-pieces and tail defects) were determined by counting a total of 200 spermatozoa under phase contrast microscopy at 1000× (Seifi-Jamadi et al., 2016b).

The data were analysed using the GLM procedure of SAS software (SAS, 2002). The dataset was checked for normal distribution using the univariate procedure and Shapiro-Wilk test and normalized through arcsine square root transformation. The results were expressed as Ismeans \pm SE. The Duncan test was applied to determine the significant differences. Linear and quadratic effects of dietary fat sources (treatment as fixed effect) were tested, using orthogonal polynomials and the level of significance was set at $P \leq 0.05$.

\section{Results}

The effects of FO and PF on the post-thaw sperm kinetics of the semen of Moghani rams are presented in Table 3. The results showed that PM, VAP, VCL (linear effect, $P=0.01$ ), and ALH (quadratic effect, $P=0.002$ ) in the group that received FO were higher than the control. Also, TM and VSL were higher in the groups that received FO and PF compared with the control (quadratic effect, $P=0.008$, and $P=0.001$, respectively). No difference was noted in STR and LIN among the groups $(P \geq 0.05)$.

Table 3 Post-thaw characteristics of semen of Moghani rams after freeze-thawing (Ismeans \pm SE)

\begin{tabular}{lccccc}
\hline \multirow{2}{*}{ Parameters } & \multicolumn{3}{c}{ Treatments } & \multicolumn{2}{c}{$P$-value } \\
\cline { 2 - 6 } & FO & Control & PF & Linear & Quadratic \\
\hline TM $(\%)$ & $58.75^{\mathrm{a}} \pm 1.69$ & $43.10^{\mathrm{b}} \pm 2.43$ & $51.93^{\mathrm{a}} \pm 1.72$ & $\mathrm{NS}$ & 0.008 \\
PM $(\%)$ & $38.25^{\mathrm{a}} \pm 1.61$ & $24.25^{\mathrm{c}} \pm 1.34$ & $31.28^{\mathrm{b}} \pm 0.87$ & 0.01 & 0.001 \\
$\operatorname{VAP}(\mu \mathrm{m} / \mathrm{s})$ & $31.63^{\mathrm{a}} \pm 0.54$ & $21.05^{\mathrm{c}} \pm 0.87$ & $29.55^{\mathrm{b}} \pm 0.39$ & 0.01 & 0.001 \\
$\operatorname{VSL}(\mu \mathrm{m} / \mathrm{s})$ & $23.33^{\mathrm{a}} \pm 0.82$ & $16.13^{\mathrm{b}} \pm 1.28$ & $21.90^{\mathrm{a}} \pm 0.49$ & $\mathrm{NS}$ & 0.001 \\
$\operatorname{VCL}(\mu \mathrm{m} / \mathrm{s})$ & $67.53^{\mathrm{a}} \pm 1.58$ & $47.73^{\mathrm{c}} \pm 1.49$ & $55.08^{\mathrm{b}} \pm 0.61$ & 0.01 & 0.001 \\
STR $(\%)$ & $70.58 \pm 3.08$ & $76.30 \pm 3.75$ & $74.20 \pm 0.61$ & $\mathrm{NS}$ & $\mathrm{NS}$ \\
LIN $(\%)$ & $30.05 \pm 1.34$ & $32.63 \pm 2.40$ & $29.75 \pm 1.71$ & $\mathrm{NS}$ & $\mathrm{NS}$ \\
ALH $(\mu \mathrm{m})$ & $1.57^{\mathrm{a}} \pm 0.01$ & $1.23^{\mathrm{b}} \pm 0.04$ & $1.48^{\mathrm{a}} \pm 0.04$ & $\mathrm{NS}$ & 0.002
\end{tabular}

ALH: amplitude of lateral head displacement; BCF: beat cross frequency; FO: fish oil; LIN: linearity; PF: Persia fat; PM: progressive motility; STR: straightness; TM: total motility; VAP: average path velocity; VCL: curvilinear velocity;, VSL: straight line velocity

Different superscripts within the same line shows significant differences $(P<0.05)$

According to the results shown in Figure 1, viability was higher in the FO group compared with the other groups (quadratic effect, $P=0.01$ ). Although the MF of the FO group was increased, there was no difference in $\mathrm{Ml}$ among the groups $(P \geq 0.05)$. Also, the sperm abnormality after the freeze-thawing process was higher in the control group compared with other groups, but there was no difference in the number of sperm abnormalities between the control and the PF group $(P \geq 0.05)$. However, the difference between control and FO group was statistically significant (quadratic effect, $P=0.03$ ).

The results of the current study showed that the group that was treated with FO had a higher sperm concentration in comparison with other groups (linear effect, $P=0.04$ ). However, there was no difference in the semen volume of rams when the FO and PF groups were compared $(P \geq 0.05)$. But the difference between the FO and PF groups and the control was statistically significant (quadratic effect, $P=0.01$ ) (Figure 2). 


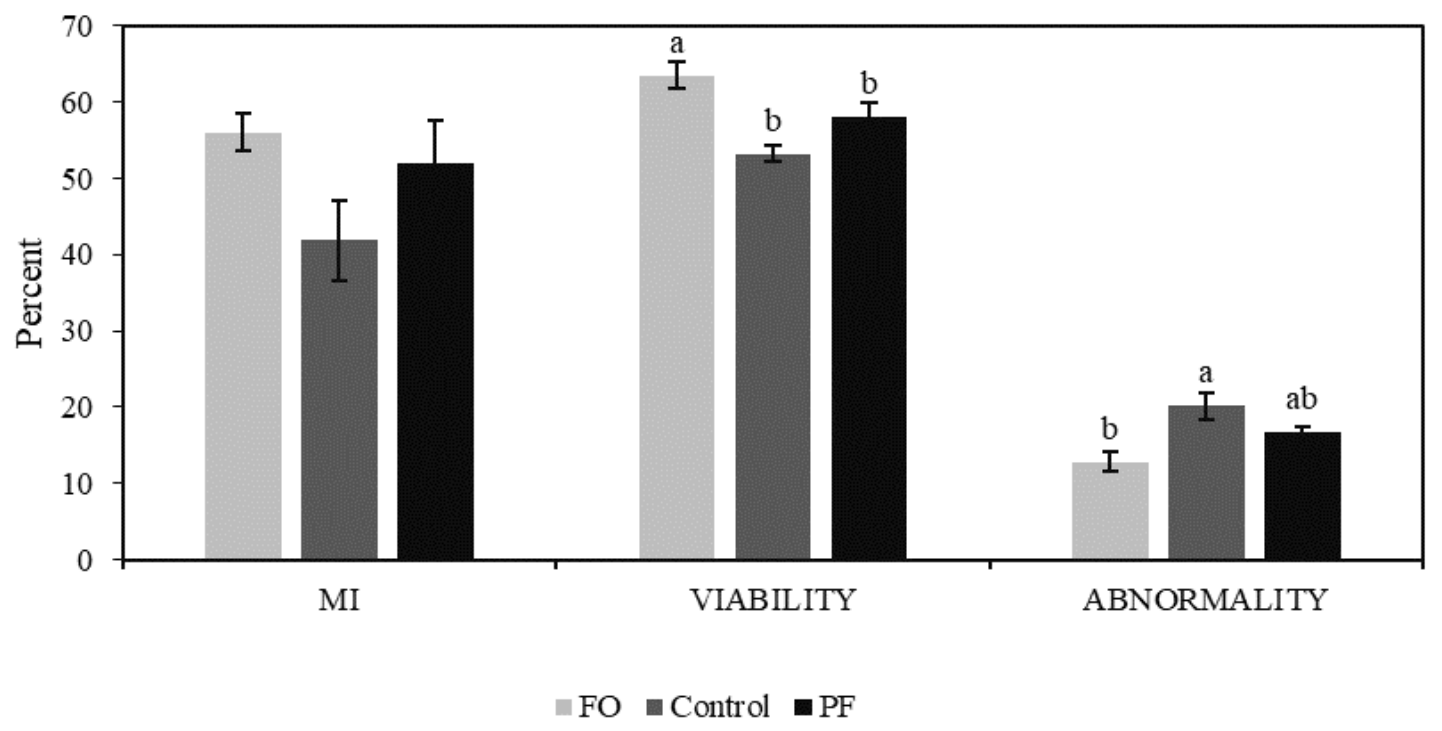

Figure 1 Effects of fish oil (FO) and Persia fat (PF) on viability, membrane functionality and abnormality of semen of Moghani rams after freeze-thawing process (Ismeans $\pm \mathrm{SE}$ )

Different superscripts in each parameter show significant differences $(P<0.05)$

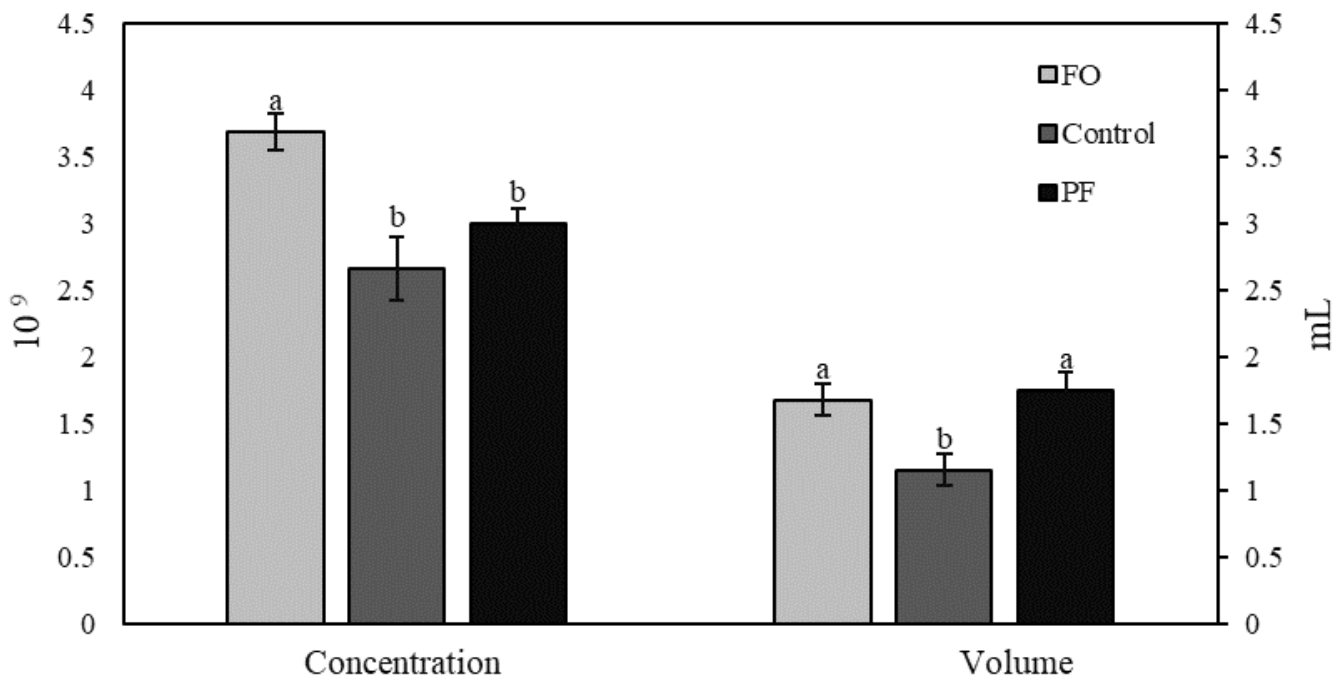

Figure 2 Effects of fish oil (FO) and Persia fat (PF)on volume and sperm concentration of semen of Moghani rams (Ismeans $\pm \mathrm{SE})$. Different superscripts shows significant differences $(P<0.05)$

\section{Discussion}

The aim of the current study was to investigate the effects of supplementing the diets of Moghani rams with three differently composed lipids on the quality of ram frozen-thawed semen. According to the literature, vertebrates cannot synthesize the n- 3 and $n-6$ series of PUFA and these elements must be obtained through a balanced diet (Cook \& McMaster, 2002). On the other hand, lipid composition of the diet could alter fatty acid composition of the semen and plasma membrane of spermatozoa (Blesbois et al., 1997). PUFAs enhance frozen (Gürler et al., 2015) or fresh (Karimi et al., 2017) sperm quality by improving the fluidity of the plasma membrane lipids of the sperm head, body and tail. Increasing fluidity is necessary for sperm motility, plasma membrane integrity and functionality.

The damage from the freezing and thawing process could decrease sperm plasma membrane functionality (Celeghini et al., 2008; Seifi-Jamadi et al., 2017). Thus, enrichment of the mammalian diet with 
unsaturated fatty acids would cause the sperm plasma membrane to better resist damage arising from the formation of ice crystals during the freezing process (Khoshvaght et al., 2016). Most mammalian species, such as bulls, rams and primates, have sperm with a high content of DHA. It follows that the loss of sperm plasma membrane PUFAs leads to a decrease in survival and fertilizing ability (Speake et al., 2003).

The results of this study showed that the groups that received FO (as a n-3 fatty acid source) and PF (source of both n-3 and n-6 fatty acids) improved total and progressive motility, viability, VSL, VCL and VAP of ram semen compared with the control group. Additionally, the $n-3$ group showed a significant increase in PM, VAP and VCL compared with the PF group. These results are similar to those of studies in boars (Rooke et al., 2001) and turkeys (Zaniboni \& Cerolini, 2009), but differ from those in stallions (Brinsko et al., 2005). The n-3 fatty acid family consists of three members, namely a-linoleic acid (ALA), docosahexaenoic acid (DHA) and eicosapentaenoic acid (EPA). The $n-6$ family consists of linoleic acid (LA) and arachidonic acid (AA) (Safarinejad et al., 2010). n-3 FAs are important in sperm membrane and acrosome integrity compared with the n-6 family. Moallem et al. (2015) demonstrated that sperm tail and head DHA content are the most important factors in enhancing the motility because of increasing the fluidity. Additionally, most DHA content is located in the sperm tail, which plays an important role in flagella function and sperm motion (Connor et al., 1998). In this regard, Ansari et al. (2012) suggested that the positive effect of n-3 on sperm quality is related to the conversion of n-3 fatty acids to DHA. According to Cerolini et al. (2006), the DHA content of the sperm decreased significantly after the freeze-thawing process, but Blesbois et al. (1997) suggested that this decrease is because of DHA's reduction of reactive oxygen species (ROS). N-3 FAs are considered potentially important antioxidants (Hodge et al., 2006). Therefore, DHA could reduce toxic ROS that arise because of the sperm freeze-thawing process (Blesbois et al., 1997).

Aksoy et al. (2006) reported that asthenozoospermic, oligozoospermic and oligoasthenozoospermic human beings had lower DHA levels than normozoospermic (Aksoy et al., 2006). The current results are in agreement with studies in ruminants (Masoudi et al., 2016; Tran et al., 2016) and humans (Vireque et al., 2016; Ferramosca et al., 2017). However, other researchers reported different results (Mourvaki et al., 2010; Karimi et al., 2017). Khoshvaght et al. (2016) concluded that feeding FO could improve the quality of fresh and frozen thawed semen by altering the sperm membrane fatty acid composition. Based on the current results, feeding the rams with the addition of FO and PF could increase the seminal volume compared with that of the control, but it did not have significant effects on sperm concentration. Karimi et al. (2017) showed that CLA could not increase bull semen volume and spermatozoa concentration. A probable reason or mechanism for seminal volume increasing with PUFAs is the synthesis and secretion of seminal plasma (Rooke et al., 2001; Khoshvaght et al., 2016). However, in some researches, this effect was not observed (Cerolini et al., 2006; Dolatpanah et al., 2008).

\section{Conclusion}

Based on the results the authors concluded that diet composition of FA could alter the quality of ram semen after the freeze-thawing process. Also, the results emphasized that enrichment of the diet of the rams with FO and PF could enhance sperm quality after the freeze-thawing process.

\section{Acknowledgements}

The authors gratefully acknowledge the support and funding received from the Faculty of Agricultural and Natural Resources, University of Mohaghegh Ardabili. Also, they thank Moghani Sheep Husbandry and Breeding Centre for providing the farm for the experiment.

\section{Authors' Contributions}

$\mathrm{NH}-\mathrm{E}$ design the study, analysed the data and wrote the manuscript. FM performed the experiment and wrote the manuscript. VV performed experiment and wrote the manuscript. BN and AS-J wrote the manuscript.

\section{Conflict of Interest Declaration}

The authors declare no competing financial interests.

\section{References}

Aksoy, Y., Aksoy, H., Altınkaynak, K., Aydın, H.R. \& Özkan, A., 2006. Sperm fatty acid composition in subfertile men. Prostaglandins Leukot. Essent. Fatty Acids. 75, 75-79.

Ansari, M., Towhidi, A., Moradi Shahrbabak, M. \& Bahreini, M., 2012. Docosahexaenoic acid and alpha-tocopherol improve sperm cryosurvival in goat. Slovak. J. Anim. Sci. 45, 7-13.

Blesbois, E., Lessire, M., Grasseau, I., Hallouis, J. \& Hermier, D., 1997. Effect of dietary fat on the fatty acid composition and fertilizing ability of fowl semen. Biol. Reprod. 56, 1216-1220.

Brinsko, SP., Varner, DD., Love, CC., Blanchard, T.L., Day, BC. \& Wilson, ME., 2005. Effect of feeding a DHA-enriched nutriceutical on the quality of fresh, cooled and frozen stallion semen. Theriogenology 63, 1519-1527. 
Björndahl, L., Söderlund, I. \& Kvist, U., 2003. Evaluation of the one-step eosin-nigrosin staining technique for human sperm vitality assessment. Human Reprod. 18, 813-816.

Celeghini, E.C.C., de Arruda, R.P., de Andrade, A.F.C., Nascimento, J., Raphael, C.F. \& Rodrigues, P.H.M., 2008. Effects that bovine sperm cryopreservation using two different extenders has on sperm membranes and chromatin. Anim. Reprod. Sci. 104, 119-131.

Cerolini, S., Zaniboni, L., Maldjian, A. \& Gliozzi, T., 2006. Effect of docosahexaenoic acid and a-tocopherol enrichment in chicken sperm on semen quality, sperm lipid composition and susceptibility to peroxidation. Theriogenology 66 , 877-886.

Connor, W.E., Lin, D.S., Wolf, D. \& Alexander, M., 1998. Uneven distribution of desmosterol and docosahexaenoic acid in the heads and tails of monkey sperm. J. Lipid Res. 39, 1404-1411.

Conquer, J.A., Martin, J.B., Tummon, I., Watson, L. \& Tekpetey, F., 2000. Effect of DHA supplementation on DHA status and sperm motility in asthenozoospermic males. Lipids 35, 149.

Cook, H.W. \& McMaster, C.R., 2002. Fatty acid desaturation and chain elongation in eukaryotes. New Compr. Biochem. 36, 181-204.

Dolatpanah, M., Towhidi, A., Farshad, A., Rashidi, A. \& Rezayazdi, A., 2008. Effects of dietary fish oil on semen quality of goats. Asian-Austral. J. Anim. Sci. 21, 29.

Ferramosca, A., Moscatelli, N., Di Giacomo, M. \& Zara, V., 2017. Dietary fatty acids influence sperm quality and function. Andrology 5, 423-430.

Gholami, H., Chamani, M., Towhidi, A. \& Fazeli, M., 2010. Effect of feeding a docosahexaenoic acid-enriched nutriceutical on the quality of fresh and frozen-thawed semen in Holstein bulls. Theriogenology 74, 1548-1558.

Gürler, H., Calisici, O., Calisici, D. \& Bollwein, H., 2015. Effects of feeding omega-3-fatty acids on fatty acid composition and quality of bovine sperm and on antioxidative capacity of bovine seminal plasma. Anim. Reprod. Sci. 160, 97-104.

Hodge, W.G., Schachter, H.M., Barnes, D., Pan, Y., Lowcock, E.C., Zhang, L., Sampson, M., Morrison, A., Tran, K. \& Miguelez, M., 2006. Efficacy of $\omega-3$ fatty acids in preventing age-related macular degeneration: A systematic review. Ophthalmology 113, 1165-1173.

Karimi, R., Towhidi, A., Zeinoaldini, S., Rezayazdi, K., Mousavi, M., Safari, H. \& Martinez-Pastor, F., 2017. Effects of supplemental conjugated linoleic acids (CLA) on fresh and post-thaw sperm quality of Holstein bulls. Reprod. Domest. Anim. 52, 459-467.

Khoshvaght, A., Towhidi, A., Zare-shahneh, A., Noruozi, M., Zhandi, M., Davachi, N.D. \& Karimi, R., 2016. Dietary n-3 PUFAs improve fresh and post-thaw semen quality in Holstein bulls via alteration of sperm fatty acid composition. Theriogenology 85, 807-812.

Masoudi, R., Sharafi, M., Shahneh, A.Z., Towhidi, A., Kohram, H., Zhandi, M., Esmaeili, V. \& Shahverdi, A., 2016. Effect of dietary fish oil supplementation on ram semen freeze ability and fertility using soybean lecithin- and egg yolkbased extenders. Theriogenology 86, 1583-1588.

Moallem, U., Neta, N., Zeron, Y., Zachut, M. \& Roth, Z., 2015. Dietary a-linolenic acid from flaxseed oil or eicosapentaenoic and docosahexaenoic acids from fish oil differentially alter fatty acid composition and characteristics of fresh and frozen-thawed bull semen. Theriogenology 83, 1110-1120.

Mourvaki, E., Cardinali, R., Dal Bosco, A., Corazzi, L. \& Castellini, C., 2010. Effects of flaxseed dietary supplementation on sperm quality and on lipid composition of sperm subfractions and prostatic granules in rabbit. Theriogenology 73, 629-637.

Najafi, A., Zhandi, M., Towhidi, A., Sharafi, M., Sharif, A.A., Motlagh, M.K. \& Martinez-Pastor, F., 2013. Trehalose and glycerol have a dose-dependent synergistic effect on the post-thawing quality of ram semen cryopreserved in a soybean lecithin-based extender. Cryobiology 66, 275-282.

Ollero, M., Gil-Guzman, E., Lopez, M.C., Sharma, R.K., Agarwal, A., Larson, K., Evenson, D., Thomas Jr, A.J. \& Alvarez, J.G., 2001. Characterization of subsets of human spermatozoa at different stages of maturation: implications in the diagnosis and treatment of male infertility. Human Reprod. 16, 1912-1921.

Rahmatzadeh, M., Kohram, H., Zare Shahneh, A., Seifi-Jamadi, A. \& Ahmad, E., 2017. Antioxidative effect of BHA in soya bean lecithin-based extender containing glycerol or DMSO on freezing capacity of goat semen. Reprod. Domest. Anim. 52, 985-991.

Rato, L., Alves, M., Cavaco, J. \& Oliveira, P., 2014. High-energy diets: a threat for male fertility? Obes. Rev. 15, 996-1007.

Rodrigues, P.G., de Moura, R.S., Rocha, L.G.P., Bottino, M.P., Nichi, M., ..., Souza, J.C., 2017. Dietary polyunsaturated fatty acid supplementation improves the quality of stallion cryopreserved semen. J. Equine Vet. Sci. 54, 18-23.

Rooke, J., Shao, C. \& Speake, B., 2001. Effects of feeding tuna oil on the lipid composition of pig spermatozoa and in vitro characteristics of semen. Reproduction 121, 315-322.

Saether, T., Tran, T.N., Rootwelt, H., Grav, H.J., Christophersen, B.O. \& Haugen, T.B., 2007. Essential fatty acid deficiency induces fatty acid desaturase expression in rat epididymis, but not in testis. Reproduction 133, 467-477.

Safarinejad, M.R., Hosseini, S.Y., Dadkhah, F. \& Asgari, M.A., 2010. Relationship of omega-3 and omega-6 fatty acids with semen characteristics, and anti-oxidant status of seminal plasma: a comparison between fertile and infertile men. Clin. Nutr. 29, 100-105.

SAS, 2002. Statistical Analysis Systems user's guide. Version 9.0 (TS M0), SAS Institute Inc., Cary, NC, USA)

Schäfer, S. \& Holzmann, A., 2000. The use of transmigration and Spermac ${ }^{\mathrm{TM}}$ stain to evaluate epididymal cat spermatozoa. Anim. Reprod. Sci. 59, 201-211. 
Seifi-Jamadi, A., Kohram, H., Zareh-Shahne, A., Ansari, M. \& Macías-García, B., 2016. Quercetin ameliorate motility in frozen-thawed turkmen stallions sperm. J. Equine Vet. Sci. 45, 73-77.

Seifi-Jamadi, A., Kohram, H., Zareh-Shahne, A., Dehghanizadeh, P. \& Ahmad, E., 2016. Effect of various concentrations of butylated hydroxyanisole and butylated hydroxytoluene on freezing capacity of turkmen stallion sperm. Anim. Reprod. Sci, 170, 108-113.

Seifi-Jamadi, A., Ahmad, E., Ansari, M. \& Kohram, H., 2017. Antioxidant effect of quercetin in an extender containing DMA or glycerol on freezing capacity of goat semen. Cryobiology 75, 15-20.

Speake, B.K., Surai, P.F., Rooke, J.A., De Vriese, S. \& Christophe, A., 2003. Regulation of avian and mammalian sperm production by dietary fatty acids. Male Fertility and Lipid Metabolism. AOCS Press, Champaign, IL, 96-117.

Tran, L., Malla, B., Sharma, A., Kumar, S., Tyagi, N. \& Tyagi, A., 2016. Effect of omega-3 and omega-6 polyunsaturated fatty acid enriched diet on plasma IGF-1 and testosterone concentration, puberty and semen quality in male buffalo. Anim. Reprod. Sci. 173, 63-72.

Uysal, O. \& Bucak, M., 2007. Effects of oxidized glutathione, bovine serum albumin, cysteine and lycopene on the quality of frozen-thawed ram semen. Acta Vet. Brno. 76, 383-390.

Vireque, A.A., Tata, A., Silva, O.F., LoTurco, E.G., Azzolini, A., Ferreira, C.R., Dantas, M.H., Ferriani, R.A. \& Reis, R.M., 2016. Effects of $n-6$ and $n-3$ polyunsaturated acid-rich soybean phosphatidylcholine on membrane lipid profile and cryotolerance of human sperm. Fertil. Steril. 106, 273-283. e6.

Wathes, D.C., Abayasekara, D.R.E. \& Aitken, R.J., 2007. Polyunsaturated fatty acids in male and female reproduction. Biol. Reprod. 77, 190-201.

World Health Organization, 2010. WHO laboratory manual for the examination and processing of human semen. WHO, Switzerland.

Zaniboni, L. \& Cerolini, S., 2009. Liquid storage of turkey semen: Changes in quality parameters, lipid composition and susceptibility to induced in vitro peroxidation in control, n-3 fatty acids and alpha-tocopherol rich spermatozoa. Anim. Reprod. Sci. 112, 51-65. 